\title{
A multi-state outbreak of Salmonella Saintpaul in Australia associated with cantaloupe consumption
}

\author{
S. A. MUNNOCH ${ }^{1}$, K. WARD ${ }^{2}$, S. SHERIDAN ${ }^{3,4,5}$, G. J. FITZSIMMONS ${ }^{6}$, \\ C. T. SHADBOLT ${ }^{7}$, J. P. PIISPANEN ${ }^{8}$, Q. WANG ${ }^{9}$, T. J. WARD ${ }^{10}$, T. L. M. WORGAN ${ }^{1}$, \\ C. OXENFORD ${ }^{11}$, J. A. MUSTO ${ }^{2}$, J. MCANULTY ${ }^{2}$ And D. N. DURRHEIM ${ }^{1 *}$ \\ ${ }^{1}$ Hunter New England Population Health, Hunter New England Area Health Service, Wallsend, NSW, Australia \\ ${ }^{2}$ Communicable Diseases Branch, New South Wales Health, North Sydney, NSW, Australia \\ ${ }^{3}$ Master of Applied Epidemiology program, National Centre for Epidemiology and Population Health, Australian \\ National University College of Medicine and Health Sciences, The Australian National University, Canberra, \\ ACT, Australia \\ ${ }^{4}$ Communicable Disease Control Unit, Department of Human Services, Melbourne, VIC, Australia \\ ${ }^{5}$ Burnet Institute, Melbourne, VIC, Australia \\ ${ }^{6}$ Office of Health Protection, Australian Government Department of Health and Ageing, Canberra, ACT, \\ Australia \\ ${ }^{7}$ New South Wales Food Authority, Newington, NSW, Australia \\ ${ }^{8}$ Tropical Population Health Unit, Northern Area Health Service, Townsville, QLD, Australia \\ ${ }^{9}$ Centre for Infectious Diseases Control and Microbiology - Public Health, Institute of Clinical Pathology \\ and Medical Research, Westmead Hospital, Westmead, NSW, Australia \\ ${ }^{10}$ Centre for Disease Control, Northern Territory Department of Health and Community Services, Darwin, \\ NT, Australia \\ ${ }^{11}$ Health Protection Service, Australian Capital Territory Health, Holder, ACT, Australia
}

(Accepted 14 May 2008; first published online 18 June 2008)

\section{SUMMARY}

A multi-state outbreak of Salmonella enterica serovar Saintpaul infection occurred in Australia during October 2006. A case-control study conducted in three affected jurisdictions, New South Wales, Victoria and Australian Capital Territory, included 36 cases with the outbreak-specific strain of $S$. Saintpaul identified by multiple locus variable-number tandem repeat analysis (MLVA) in a faecal specimen and 106 controls. Consumption of cantaloupe (rockmelon) was strongly associated with illness (adjusted OR $23.995 \%$, $95 \%$ CI 5·1-112.4). S. Saintpaul, with the outbreak MLVA profile, was detected on the skin of two cantaloupes obtained from an implicated retailer. Trace-back investigations did not identify the specific source of the outbreak strain of $S$. Saintpaul, but multiple Salmonella spp. were detected in environmental samples from farms and packing plants investigated during the trace-back operation. Cantaloupe production and processing practices pose a potential public health threat requiring regulatory and community educational interventions.

Key words: Epidemiology, food safety, foodborne diseases, outbreaks, Salmonella.

\footnotetext{
* Author for correspondence: Professor D. N. Durrheim, Hunter New England Population Health, Private Bag 10, Wallsend, 2287, New South Wales, Australia.

(Email: David.Durrheim@hnehealth.nsw.gov.au)
} 


\section{INTRODUCTION}

Salmonella enterica serovar Saintpaul (S. Saintpaul) accounted for $4 \cdot 2-5 \cdot 1 \%$ of Australian annual Salmonella notifications between 2003 and 2005 (Australian Government Department of Health and Ageing, National Notifiable Diseases Database, unpublished data.). Reports of infection with $S$. Saintpaul are more common in the northern states of Australia, Queensland and Northern Territory, and relatively uncommon in the remaining states. In Australia, foodborne outbreaks with this Salmonella serotype have previously been associated with the consumption of boiled eggs, untreated drinking water and bean sprouts [1-3]. Internationally, $S$. Saintpaul outbreaks have been attributed to the consumption of paprika and paprika-flavoured potato chips, bean sprouts, hospital prepared formula and mangoes [4-7].

Salmonellosis outbreaks associated with the consumption of fresh produce have previously been uncommon in Australia. The Australian Commonwealth Government funds and coordinates OzFoodNet, a network of foodborne disease epidemiologists based in each of Australia's eight states and territories (jurisdictions), and maintains a national database of all reported foodborne disease outbreaks. Review of OzFoodNet outbreak data found only 15 outbreak reports implicating consumption of fresh produce between 2001 and 2005, representing $2 \cdot 4 \%$ of all reported foodborne or suspected foodborne outbreaks. None of these outbreaks were associated with the consumption of cantaloupe (scientific name Cucumis melo L. var. reticulatus Naudin), which is also known as rockmelon [8]. Internationally, outbreaks of salmonellosis have been associated with the consumption of cantaloupes. A published review of the international literature and other data sources, for the period 1973-2002, identified 28 outbreaks associated with the consumption of cantaloupes, with 11 outbreaks $(39 \%)$ caused by Salmonella spp. (S. Chester, $S$. Poona, $S$. Saphra, $S$. Oranienburg, $S$. Berta and Salmonella Group E1) [9].

We describe the investigation of a large outbreak of $S$. Saintpaul, with 115 confirmed cases with the multiple locus variable-number tandem repeat analysis (MLVA)-defined outbreak-related strain, that occurred in six Australian jurisdictions with its epicentre in the south-eastern mainland jurisdictions of Australia (New South Wales, Victoria and Australian Capital Territory) between September and November
2006. In New South Wales a sudden increase in the number of human notifications of $S$. Saintpaul infection was detected through routine surveillance in late September 2006. Shortly after a national alert was issued, Victoria and the Australian Capital Territory also reported a higher number of notifications of $S$. Saintpaul infection than expected. In response, a multi-state public health investigation was initiated to identify the cause of the outbreak and risk factors for infection amenable to public health control measures.

\section{METHODS}

\section{Hypothesis generation}

Fourteen newly notified $S$. Saintpaul cases were interviewed with a standardized 7-day retrospective hypothesis generating and trawling questionnaire to identify possible foodborne and environmental risk factors for infection. Food exposures commonly reported by these cases were cantaloupe $(n=11)$, cucumber $(n=8)$, pear $(n=8)$, grapes $(n=8)$, strawberries $(n=8)$ and cooked broccoli $(n=8)$. These food items were consumed more frequently by cases than expected when compared with food consumption data for controls from an Australian Campylobacter case-control study [10].

\section{Epidemiological investigation}

A multi-jurisdictional case-control study was initiated to test the hypothesis that $S$. Saintpaul infection was associated with the consumption of fresh produce items including cantaloupe. Cases were defined as an infection with the outbreak strain of $S$. Saintpaul isolated from a faecal specimen by MLVA on or after 6 October 2006 in residents of New South Wales, Victoria and the Australian Capital Territory. Cases were identified through routine passive notification. Two control recruitment methods were used with New South Wales and the Australian Capital Territory utilizing progressive/regressive digit dialling based on the case's telephone number to select four and three controls respectively, while Victoria recruited two controls for each case using a control bank comprising consenting respondents from a state-based population health survey. Controls were selected from the same broad age band as cases ( $<16$ years or $\geqslant 16$ years), except in Victoria where ages were closely matched.

Cases were asked whether they had consumed cantaloupe, strawberries, grapes, pears, cucumber, beef 
mince, chicken or eggs (the food items identified during hypothesis-generating interviews), in the 4 days preceding onset of illness. For fruit and vegetable items they were asked whether these had been consumed alone, or in a mixed fruit juice or fruit salad. For each food item consumed, place and date of purchase and specific product handling information was sought. Identical questions were posed to controls for the 4-day period prior to interview. The three jurisdictions interviewed the cases and controls residing within their borders, and responses were entered onto NetEpi Case Manager, an open source software tool designed to allow for secure entry onto a webbased outbreak database [11].

\section{Statistical analysis}

Statistical analysis was conducted using Intercooled Stata version 8 [12]. Case and control demographic details were compared using Pearson's $\chi^{2}$ test for trend. Univariate analysis was used to calculate crude odds ratios (OR), with $95 \%$ confidence intervals (CI), for all exposures and risk factors. A maximumlikelihood logistic regression model was constructed using sequential backward elimination of variables to explore the association between food items and illness, adjusted for age group as frequency-matching was by age group $<16$ years or $\geqslant 16$ years, with food items that had a $P$ value $<0 \cdot 1$ in univariate analysis included in the model. As controls were age-matched in Victoria, matched analysis was also conducted to confirm findings.

\section{Microbiological investigation}

Patients with $S$. Saintpaul infection were identified by reference public health laboratories in New South Wales, Queensland, Victoria and South Australia. The same laboratories tested cantaloupe samples collected from retailers, wholesalers and processors implicated during the trace-back investigation.

All human isolates of $S$. Saintpaul serotyped in Australia prior to and during the outbreak period were subjected to the MLVA method adapted from Lindstedt et al. for $S$. Typhimurium [13] to determine whether they were of the outbreak-specific strain.

\section{Trace-back, sampling and environmental investigation}

Information on the places and dates of cantaloupe purchase were used by food safety regulators in each affected jurisdiction to initiate trace-back investigations. Individual retailers' records were used to identify common suppliers. Samples of cantaloupe on the day of visit at retailers and their suppliers were submitted for microbiological analysis. Records from suppliers were used to attempt to identify processors and farms that may have been the original source of implicated product.

The investigation team observed production and packing practices, and reviewed documented quality assurance procedures at processing sheds and farms that were identified as the possible source of implicated cantaloupes during the trace-back investigation. Environmental and produce samples were collected from each premises and submitted for microbiological analysis.

\section{RESULTS}

\section{Epidemiological investigation}

There were 232 S. Saintpaul cases notified in Australia during the period 1 September-30 November 2006, compared with the 5-year average for the same period of $45 \cdot 4$ cases per year (2001-2005) (Australian Government Department of Health and Ageing, National Notifiable Diseases Surveillance Scheme data: Salmonella Saintpaul notifications 2003-2006).

Thirty-six consecutive cases with the outbreak strain and 106 matched controls were recruited into the case-control study, which was conducted from 25 October to 8 November 2006 . The symptom profile of cases included diarrhoea (100\%), fever $(86 \%)$, abdominal cramps (69\%), vomiting (53\%), headache (42\%), bloody diarrhoea (36\%), nausea $(39 \%)$ and muscle/body aches $(36 \%)$. The median duration of illness was 7 days (range 3-28 days), with nine cases $(33 \%)$ requiring hospitalization. The median age for cases was 10 years (range 1-86 years), with males representing $44.4 \%$ of cases. There was no statistical difference between age group or sex for cases and controls (Table 1).

\section{Univariate analysis}

Cases were significantly more likely to have consumed cantaloupe (OR 14.60, 95\% CI 5.50-40.20) during the 4-day exposure period compared with controls. The association between illness and cantaloupe consumption was found for each jurisdiction and remained statistically significant (Table 2). Seventy-two 
Table 1. Characteristics of cases and controls recruited into the Salmonella Saintpaul study, Australia, 25 October-8 November 2006

\begin{tabular}{|c|c|c|c|c|c|}
\hline \multirow[b]{2}{*}{ Characteristic } & \multicolumn{2}{|c|}{ Case } & \multicolumn{2}{|c|}{ Control } & \multirow[b]{2}{*}{$P$ value } \\
\hline & $n$ & $(\%)$ & $n$ & $(\%)$ & \\
\hline Age (years) & & & & & $0 \cdot 86$ \\
\hline$<16$ & 21 & $58 \cdot 3$ & 60 & $56 \cdot 6$ & \\
\hline$\geqslant 16$ & 15 & $41 \cdot 7$ & 46 & $43 \cdot 4$ & \\
\hline Jurisdiction & & & & & $0 \cdot 21$ \\
\hline New South Wales & 15 & $41 \cdot 7$ & 61 & $57 \cdot 5$ & \\
\hline Victoria & 18 & $50 \cdot 0$ & 36 & $34 \cdot 0$ & \\
\hline $\begin{array}{l}\text { Australian Capital } \\
\text { Territory }\end{array}$ & 3 & $8 \cdot 3$ & 9 & $8 \cdot 5$ & \\
\hline Sex & & & & & $0 \cdot 78$ \\
\hline Male & 16 & $44 \cdot 4$ & 56 & $52 \cdot 9$ & \\
\hline Female & 20 & $55 \cdot 6$ & 50 & $47 \cdot 1$ & \\
\hline Total & 36 & & 106 & & \\
\hline
\end{tabular}

percent (26/36) of cases recollected cantaloupe consumption compared to $55 \%(20 / 36)$ for strawberry consumption, which demonstrated the second largest odds ratio. $S$. Saintpaul infection was not associated with the consumption of strawberries, raw broccoli, cucumber, pears, grapes, chicken, mince or eggs, either on their own, or, for the fruit items, as part of a mixed fruit juice or fruit salad. No association was found between $S$. Saintpaul illness and the nature of cantaloupe at purchase; half or whole fruit and refrigerated or unrefrigerated. No association was found between $S$. Saintpaul illness and whether it was stored refrigerated or unrefrigerated in the case's home; how it was prepared at home or whether it was consumed with skin removed or not removed.

When examining associations in the two age groups $(<16$ years and $\geqslant 16$ years), we found that cases aged $<16$ years were significantly more likely to have consumed cantaloupe (OR 17.0, 95\% CI 4.3-78.8), cantaloupe as part of a fruit salad (OR 10.0, 95\% CI 1.6-72.6), and strawberries (OR 3.8, 95\% CI $1 \cdot 2-13 \cdot 3)$ during the 4-day exposure period than controls, whilst for cases aged $\geqslant 16$ years, consumption of cantaloupe (OR $7 \cdot 1,95 \%$ CI $1 \cdot 7-31 \cdot 3$ ) was the only variable where a statistically significant association between exposure and illness was identified (Table 2).

\section{Multivariate analysis}

Cantaloupe (on its own and as fruit salad), strawberries (on their own and as fruit salad), pears, gender, jurisdiction and age group were included in a multivariate model. After adjusting for these factors, only consumption of cantaloupe (adjusted OR 23.9, $95 \%$ CI $5 \cdot 1-112 \cdot 4$ ) was found to be significantly associated with illness. This result was not affected by age-matched analysis.

\section{Microbiological investigation}

The outbreak strain of $S$. Saintpaul (MLVA pattern: 01-11-00-00-05) was identified as being distinct from other strains of $S$. Saintpaul that were circulating prior to and after the outbreak, from January 2003 to December 2006. During the outbreak, 115 patients in six jurisdictions were confirmed as having the outbreak strain of $S$. Saintpaul (Fig. 1). Since the outbreak in 2006, notified cases of $S$. Saintpaul have returned to baseline level.

\section{Trace-back investigation}

Thirty-three of the 36 cases confirmed with the outbreak strain of $S$. Saintpaul included in the casecontrol study were able to identify the point of sale of cantaloupe purchased prior to their onset of illness. Unfortunately mingling of cantaloupe from different processors, poor documentation by some retailers and suppliers, poor traceability of fresh produce and limited recall by some cases of the places and dates of their cantaloupe purchase complicated trace-back. As no single primary source could be reliably implicated, the six processors from two jurisdictions, Queensland and Northern Territory, that had supplied produce to the various points of sale identified by cases at the time of their purchase, were all inspected.

In total, 141 samples of whole cantaloupe, three half-cantaloupes and one cantaloupe piece were tested during the trace-back investigation and $S$. Saintpaul was detected on the skin of two cantaloupes (one whole/one half-cantaloupe) obtained from a single point of sale identified by a case. The MLVA profiles of these isolates were identical to isolates from human cases. The cantaloupes supplied to this outlet, both at the time of purchase by the case and at the time of sampling, were grown and processed in the Northern Territory. In addition, $S$. Oranienburg and $S$. Orion were detected on two samples of cantaloupe grown and processed in Queensland.

\section{Environmental investigation}

Environmental investigations with microbiological sampling were performed at the six processors in 
Table 2. Association between food items, risk factors and Salmonella Saintpaul infection: case-control study, Australia, 25 October-8 November 2006

\begin{tabular}{|c|c|c|c|c|c|c|}
\hline \multirow[b]{2}{*}{ Risk factor } & \multicolumn{2}{|c|}{ Cases } & \multicolumn{2}{|c|}{ Controls } & \multirow[b]{2}{*}{ Crude OR } & \multirow[b]{2}{*}{$95 \% \mathrm{CI}$} \\
\hline & $n$ & $\%$ & $n$ & $\%$ & & \\
\hline Raw broccoli & 10 & 28 & 17 & 16 & $2 \cdot 01$ & $0 \cdot 73-5 \cdot 32$ \\
\hline Cucumber & 13 & 36 & 37 & 35 & $1 \cdot 05$ & $0 \cdot 44-2 \cdot 47$ \\
\hline Pears & 15 & 42 & 31 & 30 & $1 \cdot 73$ & $0 \cdot 72-4 \cdot 04$ \\
\hline Strawberries & 20 & 55 & 40 & 37 & $2 \cdot 06$ & $0 \cdot 89-4 \cdot 77$ \\
\hline Grapes & 6 & 17 & 19 & 18 & $0 \cdot 92$ & $0 \cdot 27-2 \cdot 68$ \\
\hline Chicken & 28 & 77 & 84 & 79 & $0 \cdot 92$ & $0 \cdot 34-2 \cdot 66$ \\
\hline Beef mince & 21 & 58 & 54 & 51 & $1 \cdot 35$ & $0 \cdot 59-3 \cdot 14$ \\
\hline Eggs & 20 & 55 & 66 & 63 & 0.76 & $0 \cdot 33-1 \cdot 76$ \\
\hline Cantaloupes & 26 & 72 & 16 & 15 & $14 \cdot 63$ & $5 \cdot 45-40 \cdot 19$ \\
\hline \multicolumn{7}{|l|}{ Combined variables } \\
\hline Any cantaloupe & 26 & 72 & 20 & 19 & $11 \cdot 18$ & $4 \cdot 30-29 \cdot 90$ \\
\hline Any grapes & 6 & 17 & 20 & 19 & $0 \cdot 86$ & $0 \cdot 29-2 \cdot 50$ \\
\hline Any strawberries & 20 & 56 & 42 & 40 & $1 \cdot 90$ & $0 \cdot 83-4 \cdot 40$ \\
\hline Any pears & 15 & 42 & 31 & 30 & $1 \cdot 72$ & $0 \cdot 72-4 \cdot 04$ \\
\hline \multicolumn{7}{|l|}{ Any cantaloupe consumption by jurisdiction } \\
\hline Australian Capital Territory & 3 & 100 & 1 & 11 & Undefined & $3 \cdot 02-\infty$ \\
\hline Victoria & 11 & 61 & 5 & 14 & $9 \cdot 74$ & $2 \cdot 56-37 \cdot 13$ \\
\hline New South Wales & 12 & 80 & 14 & 23 & $13 \cdot 43$ & $3 \cdot 31-54 \cdot 39$ \\
\hline \multicolumn{7}{|l|}{ Any cantaloupe by age group } \\
\hline Any cantaloupe $(<16$ yr $)$ & 17 & 81 & 12 & 20 & $17 \cdot 00$ & $4 \cdot 29-78 \cdot 81$ \\
\hline Any cantaloupe $(\geqslant 16$ yr) & 9 & 56 & 7 & 15 & $7 \cdot 13$ & $1 \cdot 65-31 \cdot 30$ \\
\hline Cantaloupe in fruit salad $(<16 \mathrm{yr})$ & 6 & 46 & 7 & 54 & $10 \cdot 0$ & $1 \cdot 57-72 \cdot 57$ \\
\hline Strawberries $(<16$ yr $)$ & 15 & 71 & 22 & 37 & $3 \cdot 75$ & $1 \cdot 15-13 \cdot 33$ \\
\hline Cantaloupe $(\geqslant 16 \mathrm{yr})$ & 8 & 53 & 6 & 40 & 10 & $2 \cdot 10-47 \cdot 30$ \\
\hline Strawberries $(\geqslant 16$ yr $)$ & 4 & 26 & 16 & 35 & $0 \cdot 93$ & $0 \cdot 21-3 \cdot 68$ \\
\hline \multicolumn{7}{|l|}{ Cantaloupe variables } \\
\hline Half-cantaloupe purchased & 9 & 35 & 13 & 65 & $0 \cdot 28$ & $0 \cdot 07-1 \cdot 12$ \\
\hline Cantaloupe eaten with skin on & 7 & 30 & 3 & 21 & $1 \cdot 6$ & $0 \cdot 27-11 \cdot 60$ \\
\hline Cantaloupe stored unrefrigerated at home & 9 & 39 & 2 & 14 & $3 \cdot 85$ & $0 \cdot 59-42 \cdot 10$ \\
\hline Unrefrigerated cantaloupe purchased & 22 & 96 & 13 & 96 & $1 \cdot 69$ & $0 \cdot 02-138 \cdot 78$ \\
\hline Washed cantaloupe before eating & 10 & 43 & 3 & 21 & $2 \cdot 82$ & $0 \cdot 52-19 \cdot 46$ \\
\hline
\end{tabular}

OR, Odds ratio; CI, confidence interval.

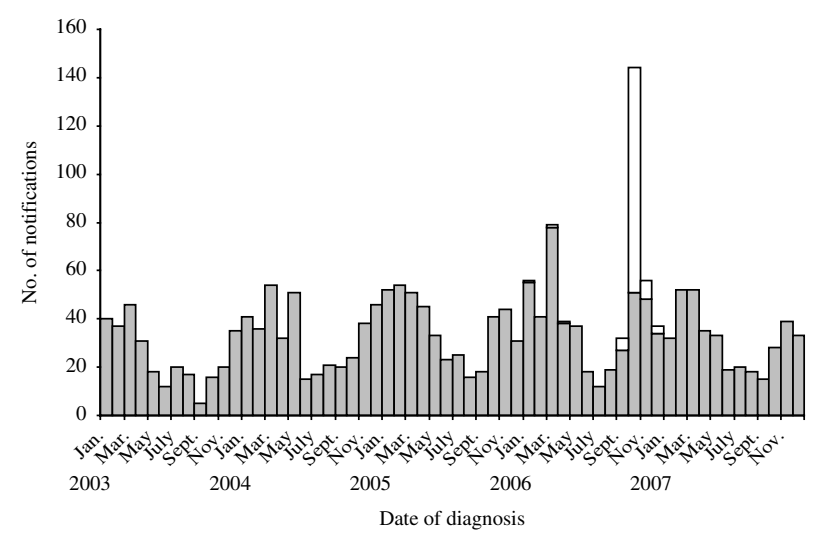

Fig. 1. Salmonella Saintpaul notifications in Australia, including those cases with the outbreak strain, 2003-2007. $\square$, Outbreak strain; $\square$, non-outbreak strains. the two jurisdictions supplying cantaloupes to implicated outlets at the time of the outbreak.

Fifty-nine environmental samples, including water, soil, fertilizers, organic material, dust, and swabs from equipment, and cantaloupe samples were collected during the investigation of farms and processors in the two jurisdictions. Salmonella spp. were detected in 13 samples from two sites, one in each jurisdiction, although $S$. Saintpaul was not detected in these samples (Table 3).

The environmental investigations in both jurisdictions identified a number of critical food safety issues during the production and processing of cantaloupes that may have contributed to the 
Table 3. Source of environmental samples with Salmonella spp. detected

\begin{tabular}{lll}
\hline \hline Jurisdiction & Type of environmental sample & Salmonella spp. detected \\
\hline A & Water (bore) & S. Mgulani \\
& Water (channel) & S. Zanzibar \\
& Water (entry wash) & S. Zanzibar \\
& Water (wash from channel) & S. Aberdeen \\
& Water (overflow sump) & S. Zanzibar \\
& Water (channel from river) & $S$. Mgulani \\
B & Dust on packing boxes & $S$. Welikade, \\
& Floor in packing shed & S. Virchow phage type 8 \\
& & $S$. Aberdeen, \\
& Stagnant water near bore & $S$. Bahrenfeld \\
& $S$. Virchow phage type 8, \\
\end{tabular}

contamination of fresh produce. These included the use of untreated or inadequately treated water on ready-to-eat cantaloupes; processors not using disinfectants according to manufacturers' instructions; temperature differentials between the fruit and wash water in which they were immersed; and processing of bruised or damaged fruits. Despite all processors having a documented quality assurance programme additional problems detected included incomplete record-keeping; presence of cattle feed bins in cantaloupe-packing sheds; cracked bore-casings on bore heads; and apparent limited appreciation of the purpose of quality assurance processes amongst growers and processors as assessed through informal discussion.

\section{DISCUSSION}

We report the first Australian Salmonella outbreak associated with the consumption of cantaloupe. The multi-state outbreak investigation coordinated by OzFoodNet identified a strong epidemiological association between $S$. Saintpaul infection and consumption of cantaloupe, with cases being 23 times more likely to have consumed cantaloupe in the 4 days prior to onset of illness than controls. This is supported by the detection of the outbreak strain of $S$. Saintpaul on the skin of two Northern Territory cantaloupes sampled from the retail venue where a case had purchased cantaloupe. However, S. Saintpaul was not isolated from environmental samples collected as part of the environmental investigation, nor was the mechanism for contamination specifically identified, which is not surprising given the $\sim 1$ month delay between cantaloupe harvesting and environmental investigation/sampling.

Although the environmental investigation was unable to identify precisely where the contamination of cantaloupes implicated in the outbreak occurred, the identification of Salmonella serotypes in environmental samples and the food hygiene and safety issues that were commonly identified in both the Northern Territory and Queensland suggest that opportunities for contamination existed before and during harvesting, and during whole cantaloupe processing, packaging or storage. Although the farms and processors had quality assurance programmes in place, it appears likely that current processes are ineffective in reducing microbiological contamination. The use of untreated water for surface irrigation and washing of cantaloupes, the potential for contamination of product in the field, temperature differentials between the fruit and wash water in which they are immersed that could facilitate transmigration of organisms from the surface to the interior of the fruit, and processing of bruised or damaged fruits found during the environmental investigation have previously been shown to facilitate the attachment and infiltration of pathogenic bacteria, including Salmonella spp. $[9,14-17]$.

The surface texture of cantaloupe rind provides an ideal surface for attachment of bacteria, due to irregular lenticles which create a net-like pattern on the skin of the fruit [18]. When open, the lenticles may provide ideal habitats for colonization by microorganisms while providing protection to bacteria against disinfection [19]. Pathogens may be introduced into the flesh of the cantaloupe when the rind is 
bruised or damaged. When cantaloupe wounds were inoculated with $S$. Poona (a Salmonella serovar associated with cantaloupe outbreaks in the United States), the pathogen was found to have migrated to a depth of 3-4 cm into the tissue after 7 days [16].

Storage time and temperature of potentially contaminated cantaloupes by wholesalers, retailers and consumers may also facilitate the growth of Salmonella spp. (including $S$. Saintpaul) on the rind or flesh of cantaloupe. Richards et al. recovered $S$. Poona from the rinds of intact cantaloupes stored up to 21 days at $4{ }^{\circ} \mathrm{C}$ or up to 14 days at $20{ }^{\circ} \mathrm{C}$ [17]. Contaminated cantaloupes may also serve as a source of cross contamination for other ready-to-eat fruit and vegetables, both in the retail and home environment $[20,21]$. This may explain why $28 \%(n=10)$ of cases with the outbreak strain of $S$. Saintpaul could not recall consuming cantaloupes or product containing cantaloupe in the 4 days prior to illness onset.

During the outbreak the Australian public were advised through media releases and interviews not to purchase bruised or damaged cantaloupe, refrigerate cut melons, discard cut fruit if left at room temperature for more than $2 \mathrm{~h}$ and avoid cross-contamination in the kitchen.

This study has several limitations. Recall of cases is always a concern in retrospective case-control studies, and in the current study may have led to an underestimate of the true association between salmonellosis and consuming cantaloupes, as the median delay from illness onset to interview of cases was 19 days (range 11-33 days). This delay was attributable to the time taken to access a medical doctor or hospital, and delays in specimen submission, laboratory identification and reporting. To optimize recall by controls, food exposure was restricted to the 4 days prior to the interview, and the seasonal nature of fresh produce may have influenced consumption patterns.

The trace-back investigation was impeded by case recall of date and place of purchase of cantaloupes, mingling of produce from different processors at the wholesale and retail level, relatively poor recordkeeping throughout the supply chain and limited product labelling. The specific source of contamination could not be identified due to the time delay between harvesting and the environmental investigation.

Although this is the first documented outbreak of gastrointestinal illness associated with cantaloupe consumption in Australia, this food item has been implicated in outbreaks in the United States [22, 23].
It appears that the association of Salmonella infection with cantaloupes is not limited to a single country or growing region but is rather related to the methods of production and harvesting of cantaloupes which may lead to contamination. This was one of four salmonellosis outbreaks detected in Australia during 2006 associated with the consumption of fresh produce items [3].

Currently, there is no national food safety legislation governing the production and processing of fresh produce, including cantaloupes, in Australia. Food Standards Australia New Zealand is in the process of developing standards to address this recently recognized local public health threat [24]. It is clear that guidelines for limiting food safety risks associated with cantaloupes are required. While consumers should be encouraged to consume fresh fruit and vegetables to maintain a healthy lifestyle, readily available advice at the point of purchase is needed to guide consumers on appropriate storage and preparation of these products. Thus, an approach from production to consumption is required to prevent future outbreaks of foodborne disease associated with cantaloupes.

\section{ACKNOWLEDGEMENTS}

The authors thank the following individuals who assisted in the outbreak investigation (in alphabetical order): Frank Beard, Robert Bell, Kerry Bell, Julie Burke, Robert Chiew, Susie Collins, Nick Corones, Barry Coombs, Alison Crombie, Victor DiPaola, Emily Davis, Ballant Eyeson-Annan, Tenille Fort, James Fielding, Kathleen Fullerton, Michelle Harlock, Geoff Hogg, Peter Howard, Jenny Jackson, Rick Jacobson, Eric Johnson, Martyn Kirk, Rod Knutson, Karin Lalor, Diane Lightfoot, Christopher Luthy, Peter Markey, Ian Marshall, Ian McKay, Tony Merritt, Lillian Mwanri, Annie Ng, Rhonda Owen, Beverley Parker, Simone Pozanski, Mark Salter, Cameron Sault, Russell Stafford, Nicola Stephens, Peter Sutherland, Lisa Szabo, Agnes Tan, Kirsten Tanner, Mary Valcanis, Christopher Villavicencio and Ian Wells. A limited review of the Victorian state data was published in a local public health bulletin, the Victorian Infectious Diseases Bulletin, as a short report.

\section{DECLARATION OF INTEREST}

None. 


\section{REFERENCES}

1. Taylor R, et al. A waterborne outbreak of Salmonella Saintpaul. Communicable Diseases Intelligence 2000; 24: 336-340.

2. OzFoodNet Working Group. Burden and causes of foodborne disease in Australia: Annual report of the OzFoodNet network, 2005. Communicable Diseases Intelligence 2006 ; 30: 278-300.

3. OzFoodNet Working Group. Monitoring the incidence and causes of diseases potentially transmitted by food in Australia: annual report of the OzFoodNet network, 2006. Communicable Diseases Intelligence 2007; 31: 345-365.

4. Beatty ME, et al. A multistate outbreak of Salmonella enterica serotype Saintpaul infections linked to mango consumption: a recurrent theme. Clinical Infectious Diseases 2004; 38 : 1337-1338.

5. Bornemann R, et al. An outbreak of Salmonella serotype Saintpaul in a children's hospital. Infection Control and Hospital Epidemiology 2002; 23: 671-676.

6. Lehmacher A, Bockemuhl J, Aleksic S. Nationwide outbreak of human salmonellosis in Germany due to contaminated paprika and paprika-powdered potato chips. Epidemiology and Infection 1995; 115: 501-511.

7. O'Mahony M, et al. An outbreak of Salmonella Saintpaul infection associated with beansprouts. Epidemiology and Infection 1990; 104: 229-235.

8. Food Standards Australia New Zealand. NUTTAB Food Composition Tables online version: Melon, Rockmelon (Canteloupe), Raw, Peeled (http://www. foodstandards.gov.au/monitoringandsurveillance/). Accessed 26 April 2007.

9. Bowen A, et al. Infections associated with cantaloupe consumption: a public health concern. Epidemiology and Infection 2006; 134: 675-685.

10. Stafford RJ, et al. A multi-centre prospective casecontrol study of campylobacter infection in persons aged 5 years and older in Australia. Epidemiology and Infection 2007 ; 135 : 978-988.

11. NetEpi. Free, open source, network-enabled tools for epidemiology and public health practice (http://www. netepi.org/). Accessed: 20 October 2006.

12. Stata statistical software. Release 8.0. Texas: College Station, 2003.

13. Lindstedt BA, et al. Multiple-locus variable-number tandem-repeats analysis of Salmonella enterica subsp. enterica serovar Typhimurium using PCR multiplexing and multicolor capillary electrophoresis. Journal of Microbiological Methods 2004; 59: 163-172.

14. Stine SW, et al. Application of microbial risk assessment to the development of standards for enteric pathogens in water used to irrigate fresh produce. Journal of Food Protection 2005; 68: 913-918.

15. Richards GM, Beuchat LR. Attachment of Salmonella Poona to cantaloupe rind and stem scar tissues as affected by temperature of fruit and inoculum. Journal of Food Protection 2004; 67: 1359-1364.

16. Richards GM, Beuchat LR. Infection of cantaloupe rind with Cladosporium cladosporioides and Penicillium expansum, and associated migration of Salmonella poona into edible tissues. International Journal of Food Microbiology 2005; 103: 1-10.

17. Richards GM, Beuchat LR. Metabiotic associations of molds and Salmonella Poona on intact and wounded cantaloupe rind. International Journal of Food Microbiology 2005; 97: 327-339.

18. Ukuku DO, Fett WF. Relationship of cell surface charge and hydrophobicity to strength of attachment of bacteria to cantaloupe rind. Journal of Food Protection 2002; 65: 1093-1099.

19. Gagliardi JV, et al. On-farm and postharvest processing sources of bacterial contamination to melon rinds. Journal of Food Protection 2003; 66: 82-87.

20. Ukuku DO, Sapers GM. Effect of sanitizer treatments on Salmonella Stanley attached to the surface of cantaloupe and cell transfer to fresh-cut tissues during cutting practices. Journal of Food Protection 2001; 64: 1286-1291.

21. Ukuku DO, Pilizota V, Sapers GM. Effect of hot water and hydrogen peroxide treatments on survival of salmonella and microbial quality of whole and fresh-cut cantaloupe. Journal of Food Protection 2004; 67: 432437.

22. Centers for Disease Control and Prevention. Multistate outbreaks of Salmonella serotype Poona infections associated with eating cantaloupe from Mexico-United States and Canada, 2000-2002. Morbidity and Mortality Weekly Report 2002; 51: 1044-1047.

23. Mohle-Boetani JC, et al. An outbreak of Salmonella serogroup Saphra due to cantaloupes from Mexico. Journal of Infectious Diseases 1999; 180: 1361-1364.

24. Food Standards Australia New Zealand. Food Standards News No. 62. 2007. (http://www.foodstandards.gov.au/ newsroom/foodstandardsnews/foodstandardsnews62o 3739.cfm). Accessed 29 October 2007. 